\title{
Web based Clinical Skills Teaching: Extending the Frontiers of Clinical Skills Education in Poor Settings
}

\author{
Jerome Addah \\ Department of Community \\ Medicine, \\ School of Medicine and Health \\ Sciences \\ University for Development \\ Studies, \\ Tamale Ghana West Africa \\ Post Office Box TL 1883
}

\author{
Stephen Apanga \\ Department of Community \\ Medicine, \\ School of Medicine and Health \\ Sciences \\ University for Development \\ Studies, \\ Tamale Ghana West Africa \\ Post Office Box TL 1883
}

\author{
Sam Bugri \\ Department of Community Medicine \\ School of Medicine and Health \\ Sciences \\ University for Development Studies, \\ Tamale Ghana West Africa \\ Post Office Box TL 1883
}

\begin{abstract}
The advent of the web has opened up new possibilities in the provision of mass education that were hitherto imagined, one of the drivers responsible for this new innovations is the enormous reach of the web, today a lot more people are gaining certification and degrees through accredited programs delivered over the web. The objective of the current study therefore is to explore the possibility of harness the ubiquitous presence of the web in poor settings to open up a new frontier for clinical skills education. Results from the study suggest the existence of favorable factors such as: an established culture of computer use, a technically skilled student body, and the availability of appropriate technology. Within the remit of a careful blend with bedside clinical skills teaching approaches, the above mentioned factors provide an enabling environment for establishing a web based clinical skills teaching platform.
\end{abstract}

\section{Keywords}

Web based learning in poor settings, clinical skills teaching in Africa. Ghana

\section{INTRODUCTION}

The capacity to perform a particular task acquired through routine practice and the application of specialized knowledge is generally termed a skill [1]. The range of skills needed during situations of patient encounter (Clinical Skills) are categorized into psychomotor (manual skills that demand coordination between the brain and hands in clinical care settings, such as stitching a wound), cognitive (thinking skills, such as deciding whether to conduct a surgical operation or not, or making differential diagnosis), and communication (transferring information to others, such as taking a history, explaining a procedure to a patient, breaking bad news or encouraging lifestyle modifications). Significant deficits in clinical skills continue to be registered among medical students and graduate doctors in developing countries [2-4]. Bedside teaching which is the traditional means of acquiring such skills in most of these countries is also witnessing a decline, from a percentage of $70 \%$ in the 1960 's to less than $20 \%$ in recent times[5]. Notwithstanding recent advances in instrumental diagnostic technology, the possession of clinical skills by physicians continues to be critically important to the care of patients, especially in developing countries [6]. Despite known limitations [7]. Contemporal studies continue to attest to the importance of clinical skills as diagnostic tools available to clinicians[6].

Clinical skills teaching is usually accomplished in three steps; description, demonstration, and practice [8]. The importance, indications of use, methods, and stages of a skills performance are first of all vividly described, then followed by a correct visual demonstration of the skill with explanations of each step and emphasis on take home points [8]. the ability to effectively description and demonstrate a skill depends on a teachers abilities acquired through practice and good preparation prior to sessions, unfortunately not all teachers are endowed with this abilities; so demonstration sessions sometimes become lengthy lectures leaving little or no time for student practice [8]. Consequently practice sessions are either unsupervised or delayed, in delayed sessions students usually have to rely on their long term memory to remember what to do.

An inherent weakness in this method of teaching clinical skills is the inability to provide standardized teaching and learing opportunities for all students [9]. Standardizing the teaching and learning experience is critically important especially for poor settings, where shortage of personnel and resources is endemic. In view of this clinical simulation has been adopted as a means to standardize teaching and learning opportunities [10]. It employs techniques that mimic clinical task and settings in a manner that facilitate learning of the clinical skills required for health care $[11,12]$. Simulation based teaching standardizes the educational process by providing consistent and reproducible teaching and learning experiences for all students[9].Apart from offering learners a safe environment for practice and error [12, 13], simulation training is based on active and adult learning theories [10] Dale et al showed the learning curve for active learning was higher than passive learning, they went further to also show that learners remember $90 \%$ of what they do by active learning [14]. Evaluators have also used simulation - based technology to provide consistent evaluation problems for every examinee, thereby minimizing the variability inherent in actual patient encounters [15] this reproducibility is vital especially in situations where high stake decisions such as certification or licensure depend on such assessment[16]. Common clinical simulation based technology include mannequin - type, screen based virtual reality -type, and Standardized Patients $[9,10]$. These technologies are either 
been implemented in a skills laboratory [10], or a clinical skills center [17].

In the face of the limitations posed by the traditional methods of clinical skills education, clinical skills centers have served as one of the effective and viable alternative environments for clinical skills teaching [8]. In the developing world, the introduction of clinical skills centers is usually associated with curricula changes, in the few instances where the perceived need was non-curricula a heightened risk for acquiring infectious diseases such as HIV and cultural considerations have been the main drivers [17]. In spite of the advantages of clinical skills centers, there has not been wide spread adoption in developing countries, due to financial and other resource constraints (Ref).

Over the last decade, web based learning has emerged as an efficient and economical learning environment for delivering course content, especially over geographically dispersed campuses (Ref). Web-based learning environments have gained popularity in the delivery of undergraduate medical education curricula [18], and is now been used for delivering clinical skills lessons(shoestring paper). Web- based clinical skills teaching present obvious advantages that can be harnessed by medical schools in poor settings, it is however not clear if these settings are ready to embrace such innovative learning environments. The goal of the current study therefore is to determine whether medical students as major stakeholders in the medical educational process are ready for web-based clinical skills teaching.

\section{METHODS AND MATERIALS}

This study is the result of a survey among clinical - year students in a Ghanaian Medical School using a questionnaire designed to investigate attitudes towards web based clinical skills teaching, as well as web related skills. Students who retuned their questionnaires were taught to have given their consent to be part of the study.

\subsection{Setting and Participants}

A cohort of 175 clinical year students of the School of Medicine and Health Sciences, University for Development Studies, Tamale, Ghana. The students were informed of the Purpose of the study, the requirement to complete a questionnaire, and the general content of the questionnaire. They were also told that their participation in the study was voluntary and that no personal identifiable information was going to be taken. The University for Development studies, Tamale is located in the north of Ghana and is one of the third generations of tertiary Universities to be established in the country. At the moment, the medical school has no public access to computers for medical students, it however provides broadband internet access for staff and students, and computers are not available in the library for students to use, currently the University has eight faculties spread throughout four campuses. All students at the medical school take a mandatory course in basic ICT skills (introduction to computers, and the internet, windows, Microsoft application programs) at the beginning of their University studies.

\subsection{Survey Instrument}

The students were asked the following questions pertaining to: instructional methods, educational tools, ICT skill types: Basic (able to do basic word processing and use the internet), Intermediate (Have mastered the basics and have developed additional skills, including the use of different software programs), Advanced (Knowledgeable about hardware and software), ability to perform certain task with computers. A drafted version of the questionnaire was administered to students $(\mathrm{n}=100)$ in June, 2012. Internal reliability (Cronbach's alpha) obtained from combining items with ordinal responses was $0.82(95 \% \mathrm{CI})$ for intra class correlation coefficient; 0.79 to 0.88 . The questionnaires were administered to the students who consented to participate in the study.

\subsection{Data Analysis}

Statistical analysis was performed using STATA (version 11.0, StataCorp. 2009). In order to identify medical students' preference and attitudes, an analysis of frequencies of items derived from responses to questions related to 'educational tools' and ICT skills was undertaken. Categorical variables were analyzed using chi-square.

\section{RESULTS}

All together a total of 175 questionnaires were administered, out of this, questionnaires from 129 (73.7\%) students were retrieved, out of which four questionnaires were deemed to be incomplete and therefore were not included in the analysis, leaving 125 complete and analyzable questionnaires, this resulted in a $(71.4 \%)$ response rate. The mean age for this cohort of students was determined to be 25.0 years with a distribution of $25.0 \pm 1.3$ (Mean \pm Standard deviation). Predominately they were more males $(54.4 \%)$ than females $(45.6 \%)$ as shown in Table1, of the three clinical year groups 42.4percent were respondents in year one, while the second and third year classes were equally represented.

Table1 - Participant Demographics $(n=125)$

\begin{tabular}{|c|c|}
\hline & $\mathrm{n}(\%)$ \\
\hline Age & $25 \pm 1.3$ \\
\hline \multicolumn{2}{|l|}{ Gender } \\
\hline Female & $57(45.6 \%)$ \\
\hline Male & $68(54.4 \%)$ \\
\hline \multicolumn{2}{|c|}{ Year in Clinical Training } \\
\hline Year One & $53(42.4 \%)$ \\
\hline Year Two & $36(28.8 \%)$ \\
\hline Year Three & $36(28.8 \%)$ \\
\hline
\end{tabular}


After taking inventory of the information communication technology facilities owned and accessible to students as depicted in Table2, it was realized that the most commonly owned computer type was windows based Personal Computers (96.0\%). Most students identified the CD-ROM followed by an inbuilt modem as features on their computers, more females $(94.7 \%)$, than males $(92.6 \%)$ indicated that their computers had a CD-ROM, a similar trend was observed in regard to an inbuilt modem, an internet stick modem was the prime means of accessing the internet $(52.0 \%)$, about a third of the students(34.4\%) said they accessed the internet through a local area network(Table2).

Table2- Stratification of ICT Resources own and available to study participants(n=125) by gender

\begin{tabular}{|c|c|c|c|}
\hline & Total $(n=125)$ & Females $(\mathrm{n}=57)$ & Males $(n=68)$ \\
\hline \multicolumn{4}{|l|}{ Type of Computer owned } \\
\hline PC Windows & $120(96.0 \%)$ & $55(96.5 \%)$ & $65(95.6 \%)$ \\
\hline Mac & $2(1.6 \%)$ & $0(0.0 \%)$ & $2(2.9 \%)$ \\
\hline \multicolumn{4}{|l|}{ Computer features } \\
\hline CDRom & $117(93.6 \%)$ & $54(94.7 \%)$ & $63(92.6 \%)$ \\
\hline Modem (inbuilt) & $75(60.0 \%)$ & $36(63.2 \%)$ & $39(57.4 \%)$ \\
\hline \multicolumn{4}{|l|}{ Access to the Internet } \\
\hline Local Area Connection & $43(34.4 \%)$ & $24(42.1 \%)$ & $19(27.9 \%)$ \\
\hline Internet Modem(External) & $65(52.0 \%)$ & $36(63.2 \%)$ & $29(42.6 \%)$ \\
\hline
\end{tabular}

Analysis of the variables appraising the web related skills of responding students, showed significant gender differences in competence across the range of web-related skills (Network access, Clinical computing and Online access) they students were evaluated on (Table3). a little over a third of the students $(46.4 \%)$ reported proficiency in changing a network access password, proportional differences with respect to gender was however not significant, self-assessed competence in the other skill types was as follows: $\log$ in $(45.1 \%)$ and $\log$ out $(44.8 \%)$ of a network, having access to files on a shared network(31.2\%), ability to share network files using the public folder $(25.6 \%)$, gender differences in relation to this skills were found to be significant for all but one of these skill types (access files on a shared network) more males than females self-assessed themselves as proficient

Table 3 - A contingency table describing the network access, and Clinical computing skills of participants categorized by gender

\begin{tabular}{|c|c|c|c|c|}
\hline & $\begin{array}{l}\text { Total } \\
(n=125)\end{array}$ & Female $(\mathrm{n}=57)$ & Males $(n=68)$ & P- Value \\
\hline & & CAN DO & CAN DO & \\
\hline \multicolumn{5}{|l|}{ Local area network access skills } \\
\hline Log into a network & $57(45.6 \%)$ & $20(35.1 \%)$ & $37(54.4 \%)$ & 0.0307 \\
\hline Log out of network & $56(44.8 \%)$ & $20(35.1 \%)$ & $36(52.9 \%)$ & 0.046 \\
\hline Change passwords & $58(46.4 \%)$ & $29(50.9 \%)$ & $29(42.6)$ & 0.358 \\
\hline Access files on a shared network & $39(31.2 \%)$ & $24(42.1 \%)$ & $15(22.1 \%)$ & 0.016 \\
\hline Use the public folder to share network files & $32(25.6 \%)$ & $9(15.8 \%)$ & $23(33.8 \%)$ & 0.021 \\
\hline \multicolumn{5}{|l|}{ Clinical Computing Skills } \\
\hline Use a clinical business billing system & $10(8.0 \%)$ & $8(14.0 \%)$ & $2(2.9 \%)$ & 0.023 \\
\hline Use medical records & $16(12.8 \%)$ & $12(21.1 \%)$ & $4(5.9 \%)$ & 0.012 \\
\hline Access patient info in a clinical info system & $16(12.8 \%)$ & $8(14.0 \%)$ & $8(11.8 \%)$ & 0.705 \\
\hline Use a decision support system & $12(9.6 \%)$ & $5(8.8 \%)$ & $7(10.3 \%)$ & 0.774 \\
\hline Use a CDRom (Sat-REF) to acces info & $31(24.8 \%)$ & $9(15.8 \%)$ & $22(32.4 \%)$ & 0.033 \\
\hline Use a drug interraction program(Ask $\mathrm{Rx})$ & $18(14.4 \%)$ & $5(8.8 \%)$ & $13(19.1 \%)$ & 0.101 \\
\hline
\end{tabular}

They were few instances in which gender differences in proficiency in clinical computing was significant; $12.8 \%$ and $8.4 \%$ of respondents reported been proficient in using a medical record system and a clinical business billing system respectively, gender differences regarding this skill types were found to be significant as well, this was true in regard to been able to access patient information in a clinical information system. 
Few students reported accessing clinical skills lessons online $(14.4 \%)$, significantly more females $(22.8 \%)$ than males $(7.4 \%)$ did so. Significant gender differences were also registered with respect to responding students web related skills and experiences. Sizable proportions of the students indicated they could conduct searches on the world wide web for information (40.8\%), use a web browser (37.6\%) access discussion groups $(20.8 \%)$, subscribe to and unsubscribe from a discussion group (15.2\%), as part from been able to access discussion group, males were proportionally dominant in proficiency in the other skill domain.

Table4- Web related Skills \& Experience of study participants(n=125)

\begin{tabular}{|l|l|l|l|l|}
\hline & Total $(\mathrm{n}=125)$ & $\begin{array}{l}\text { Females } \\
(\mathrm{n}=57)\end{array}$ & Males (n=68) & Palue \\
\hline Use a web browser (I.E) to access the world wide web & $47(37.6 \%)$ & $16(28.1 \%)$ & $31(45.6 \%)$ & 0.044 \\
\hline Use a browser to search for information on WWW & $51(40.8 \%)$ & $17(29.8 \%)$ & $34(50.0 \%)$ & 0.022 \\
\hline Access usenet discussion groups & $26(20.8 \%)$ & $17(29.8 \%)$ & $9(13.2 \%)$ & 0.023 \\
\hline $\begin{array}{l}\text { Subscribe to and Unsubscribe from a listserv(Email } \\
\text { discussion group) }\end{array}$ & $19(15.2 \%)$ & $4(7.0 \%)$ & $15(22.1 \%)$ & 0.020 \\
\hline Ever accessed clinical skills lessons online & $18(14.4 \%)$ & $13(22.8 \%)$ & $5(7.4 \%)$ & 0.014 \\
\hline
\end{tabular}

\section{DISCUSSION}

Regionally and internationally medical schools are incorporating curricula changes aimed at enhancing the teaching and learning of clinical skills, this changes embody new philosophical approaches to medical education, such as self-directed study, problem-based learning and structured clinical experience [19]. To accommodate this changes new learning environments that promote active participation through repeated practice, and experience sharing have been adopted [20]. One of such environments is the web. The web provides an opportunity to bypass the limitations present in the traditional methods of clinical skills teaching [21].

In pursuance of this a clinical skill teaching model informed by standardized teaching and feedback methods based on sound educational principles that facilitate the delivery of skills lesson outside a physical structure may be developed [17] and implemented over the web, such a model may be more appropriate for clinical skills teaching in poor settings. The World Wide Web is now been used to deliver course content in medical and nursing programs [22].Such innovative learning environments have been cited by [23] as enabling active participation, while encouraging shared experience and serving as motivation for students. Also the ubiquitous nature of the web makes it readily accessible and responsive to some of the environmental and resource constrains present in poor settings [24]. In such settings, hostel facilities are usually not on campus or near clinical sites, resulting in poor class attendance [21].

Virtual reality models of patients and clinical task can be designed and made available on the web by means of a web server, coupled with interactive information together with visuals, vivid descriptions and demonstrations of both noninvasive and invasive clinical procedures [25], this can be accessed by students irrespective of their location. Such simulation technology can be used at any time and it can seamlessly be integrated into the curricula of medical schools. An added advantage is that this model can be used by many learners simultaneously [10]. Simmons and colleagues [26], report that, their experience of such models, suggest that success depends on factors such as; instructional design, faculty, - student interactions, technology management skills, and student outcome evaluations.
To interact effectively with course content made available through the web, it's important that medical students have the skills, and material resources, needed to access such content [27]. Our results indicated high web literacy skills (ability to access the web and retrieve user defined content), good remote file management skills (ability to access a public folder or share documents remotely), this observed proficiency is in conformity with results from another study among this students [27]. The reported high web - related proficiency is a good indicator that a potential web based learning environment would be patronized by students [28], since they can easily access instructional material such as manuals, posted assignments, and clinical skills lessons. Our beliefs are corroborated by the findings of Potomkova and colleagues [22], that students tend to prefer web based learning environments compared to traditional lecture based classes. Our results suggest similar inclinations among our students; we observed that significant numbers of them are already accessing clinical skills lessons from the web. An indication of the existence of a web based learning culture within the student body, this suggest that attempts to introduce web based learning would be well received by students.

Outside the wards of hospitals, clinical skills centers have served as safe learning environments where errors are permissible, without concerns over causing injury or distress to patients, as is the case with traditional clinical teaching methods[29, 30]. Lowry [31] reiterate that in such environments students are at ease to learn at their own pace, with rehearsal opportunities for difficult, painful, and embarrassing skills. Skills center facilities enable teachers to use teaching tools that are amenable to structure and restructure to provide standardized and reproducible teaching and learning experiences [30]. Most of the successes with skills centers have been reported in Europe and North America [17]. Replicating these successes in poor settings require a delicate balance between idealism and pragmatism [17]. Stark and colleagues [17] report that in such settings initial set - up cost usually exceed local budgets, and even in situations where external funding is available several hurdles, such as, purchasing of equipment, long delivery time for replacement parts, and local unavailability of consumable supplies still remain. Trans et al. [32] argue that cost concerns over equipment may be overcome by using Teacher made models, though a laudable innovation, more research is needed to ascertain their validity. Another concern with 
teaching clinical skills in clinical skills centers for poor settings is the organization of evaluations, such programs are usually synchronous requiring observing faculty, students, simulators and coordinating staff to be in one location at the same time, these interactions are also always conducted with a single learner, limiting the number of learners that can be accommodated at any given time, this requires a lot of money and personnel; resources usually lacking in poor settings.

\section{CONCLUSION}

This study though based on a single study has established that web based clinical skills teaching is viable alternative to traditional clinical skills teaching methods in poor settings. Nonetheless reported inconsistencies in pedagogical advantages with web based clinical skills teaching suggest that such an innovation would be more effective as an adjunct to existing skills teaching methodologies. Taking a cue from this, skills instruction (description and demonstration) may be accomplished through the web, while practice sessions are undertaking in the wards, such a synergy would decrease teaching hours while accommodating large student numbers [33].

\section{ACKNOWLEDGMENTS}

The students who willing participated in this study are greatly indebted,

\section{REFERENCES}

[1] Abbatt F. Teaching for better learning. In. Second Edition. . ed: World Health Organization.; 1992. p. 7488.

[2] Ahmed A. Deficiencies of history-taking among medical students. Saudi Med J 12002;23: 991-994.

[3] Ahmed A. Deficiencies of physical examination among medical students. Saudi Med J 12003;24: 108- 111.

[4] Ahmed A. Deficiencies of physical examination of the nervous system among medical students. Neurosciences 12004.; 9: 447-449.

[5] LaCombe M, . On bedside teaching. Ann Intern Med 11997;;26 217-20.

[6] Holmboe E. Faculty and the observation of trainees' clinical skills: problems and opportunities. Acad Med 12004;79: 16-22.

[7] McGee S. Evidenced-based Physical Diagnosis: Philadelphia: WB Saunders,; 2001.

[8] Ahmed AM. Role of Clinical Skills Centers in Maintaining and Promoting Clinical Teaching. Sudanese Journal of Public Health 12009;4.

[9] Triola M, Feldman, H, Kalet, AL, Zabar, S, Kachur, SEK Gillespie, C Anderson, M, Griesser,C Lipkin, M. A Randomized Trial of Teaching Clinical Skills Using Virtual and Live Standardized Patients. J Gen Intern Med. : 12006;21: 424-429. .

[10] Akaike M, Fukutomi,M, Nagamune M, ,Fujimoto, A, Tsuji A I, K, Iwata, T. Simulation-based medical education in clinical skills laboratory. The Journal of Medical Investigation 12012;59 28 -35.

[11] Bradley P. The history of simulation in medical education and possible future directions. MedbEdu 12006;40: : 254-262,.

[12] Ruddy R, Patterson, MD : . Medical simulation: a tool for recognition of and response to risk. Pediatr Radio 12008; (Suppl 4) S700-6,

[13] Okuda Y, Bryson EO, DeMaria S Jr, Jacobson, L QJ, Shen B, Levine AI : : , . The utility of simulation in medical education : what is the evidence? Mt Sinai J Med 12009;76: 330-343.

[14] Sprawls P, : e. Evolving models for medical physics education and training : a global perspective. Biomed Imaging Interv J 12008;4 e16.

[15] Langsley D. Medical competence and performance assessment. A new era.. JAMA 11991;266 977-80.

[16] Scalese R, , Vivian T. Obeso, VT S. Barry Issenberg,SB. Simulation Technology for Skills Training and Competency Assessment in Medical Education. J Gen Intern Med. : 12008;23: 46-49.

[17] Stark PF, F. Teaching Clinical Skills in Developing Countries: Are Clinical Skills Centres the Answer? Education for Health 12003 :;16: 298-306.

[18] Greenhalgh T. Computer assisted learning in undergraduate medical education. BMJ 12001;322: 40-4.

[19] Rees L, Jolly B.. Medical education into the next century: Oxford (UK): Oxford University Press; ; 1998.

[20] Gallgher J. Web-based vs traditional classroom instruction in gerontology: a pilot study. J Dent Hyg. : 12005;79: 7 .

[21] Addah J. Student Attitudes towards Computer Assisted Learning: Scaling-up Medical Education in a Poor Setting. nternational Journal of Computer Applications 12012;50(22):: 35-40.

[22] Potomkova J, Mihal, V, Cihalik, C. web based instruction and its impact on the learning activity of medical students: a review. Biomed Pap Med Fac Univ Palacky Olomouc Czech Repub 12006;150: 357 - 361.

[23] Perlman C, Weston C, Gisel E. ;. A web based tutorial to enhance student learning of activity analysis. Can J Occup Thera 1 2005;72: 153-163.

[24] McEnery K. A method for interactive medical instruction utilizing the World Wide Web. In; . 1995; . p. 502-7.

[25] Palter V, Grantcharov TP: . , . Simulation in surgical education. CMAJ : 12010;182: 1191-6.

[26] Simmons C, Nyhof-Young J, Bradley J. Shoestring budgets, band-AIDS, and team work: challenges and motivators in the development of a Web-based resource for undergraduate clinical skills teaching. J Med Internet Res.. 12005 7: e14.

[27] Addah J. Proficiency in Information Communication Technology and its Use: A Survey among Clinical Students in a Ghanaian Medical School. International Journal of Computer Applications 1 2012; 45: 14-20,

[28] Fadeyi A, Desalu OO, Ameen A, Muhammed, , Adeboye AN. The reported preparedness and disposition by students in a Nigerian university towards the use of information technology for medical education. . Ann Afr Med 12010;9: 129-34.

[29] Blight J, :. The clinical skills unit. Postgrad Med J 11995;;71: 730-5.

[30] Dent J. Current trends and future implications in the developing role of clinical skills centers. Med Teach. $12001 ; 23:$ : 483-489.

[31] Lowry S. Trends in health care and their effects on medical education. BMJ 11993;306: 255-258.

[32] Tran T, Scherpbier A, Van Dalen J, Wright PE. Teachermade models: the answer for medical skills training in developing countries? BMC Med Educ. $12012 ; 12: 98$.

[33] Hopkins R, Regehr, G. Wilson, TD. Exploring the changing Learning Environment of the Gross Anatomy Lab. Acad Med 12011;86: 883 - 887. 